Suppression of pro-inflammatory cytokine release by selective inhibition of inducible nitric oxide synthase in mucosal explants from patients with ulcerative colitis

Kankuri, E

2003

Kankuri, E, Hamalainen, M , Hukkanen, M , Salmenpera , P , Kivilaakso , E, Vapaatalo, H \& Moilanen, E 2003, ' Suppression of pro-inflammatory cytokine release by selective inhibition of inducible nitric oxide synthase in mucosal explants from patients with ulcerative colitis ' , Scandinavian Journal of Gastroenterology , vol. 38 , pp. 186-192 .

http://hdl.handle.net/10138/33844

acceptedVersion

Downloaded from Helda, University of Helsinki institutional repository.

This is an electronic reprint of the original article.

This reprint may differ from the original in pagination and typographic detail.

Please cite the original version. 


\title{
Suppression of Pro-Inflammatory Cytokine Release by Selective Inhibition of Inducible Nitric Oxide Synthase in Mucosal Explants from Patients with Ulcerative Colitis
}

\author{
E. Kankuri, M. Hämäläinen, M. Hukkanen, P. Salmenperä, E. Kivilaakso, H. Vapaatalo \& \\ E. Moilanen \\ Institute of Biomedicine, Pharmacology, University of Helsinki, Finland; The Immunopharmacological \\ Research Group, Medical School, University of Tampere, Tampere University Hospital, Finland; \\ Institute of Biomedicine, Anatomy, University of Helsinki, Finland; ORTON Research Institute, \\ The Invalid Foundation, Finland; Second Dept. of Surgery, Helsinki University Central Hospital, \\ Finland
}

\begin{abstract}
Kankuri E, Hämäläinen M, Hukkanen M, Salmenperä P, Kivilaakso E, Vapaatalo H, Moilanen E. Suppression of pro-inflammatory cytokine release by selective inhibition of inducible nitric oxide synthase in mucosal explants from patients with ulcerative colitis. Scand J Gastroenterol 2003;38:186192.

Background: In ulcerative colitis (UC), inflammatory damage is associated with increased production of pro-inflammatory cytokines and nitric oxide through the inducible nitric oxide synthase (iNOS) pathway. In an animal model of acute experimental colitis we have previously shown amelioration of inflammation with the highly selective iNOS inhibitor $1400 \mathrm{~W}$. The aim of the present study was to investigate the effects of selective iNOS inhibition on the production of pro-inflammatory cytokines by the colon mucosa in UC. Methods: Inflamed and uninflamed mucosa from patients with severe UC were incubated with a highly selective iNOS inhibitor N-[3-(aminomethyl)benzyl]acetamidine $(1400 \mathrm{~W})$, with a relatively selective cNOS inhibitor N(G)-nitro-L-arginine-methyl-esther (L-NAME), or with an NO-donor, S-nitroso-acetylpenicillamine (SNAP). Cytokine concentrations in the incubation medium were quantitated with ELISA. Results: Compared to uninflamed mucosa there was an increase in iNOS protein and nitrotyrosine levels in inflamed mucosal samples. Immunolocalization of iNOS and nitrotyrosine showed their expression in inflammatory cells in the lamina propria. Expression of iNOS was also found in the epithelial brush border. Selective inhibition of iNOS suppressed the release of tumour necrosis factor alpha (TNF- $\alpha$, by 66\%) and interleukin-6 (IL-6, by 27\%). The NO-donor, SNAP, augmented the secretion of TNF- $\alpha$, IL- 6 and IL-1- $\beta$ (by $62 \%, 52 \%$ and $175 \%$, respectively) and decreased the release of IL-1 receptor antagonist (IL-1Ra, by 34\%) by the inflamed mucosa. Moreover, in uninflamed samples, $1400 \mathrm{~W}$ suppressed the production of TNF- $\alpha$ (by 69\%) and incubation with SNAP decreased IL- 6 concentrations by $48 \%$. The cNOS over iNOS selective inhibitor L-NAME had no significant effects on the accumulation of cytokines. Conclusion: Selective inhibition of iNOS suppresses mucosal TNF- $\alpha$ and IL-6 release in active UC, whereas NO seems to exacerbate the inflammatory response. These results suggest that selective iNOS inhibition may have therapeutic promise in the treatment of UC.
\end{abstract}

Key words: Anti-inflammatory drugs; inducible nitric oxide synthase; nitric oxide; NOS inhibitors; proinflammatory cytokines; ulcerative colitis

Esko Kankuri, University of Helsinki, Institute of Biomedicine, Pharmacology, BIOMEDICUM Helsinki, P.O. Box 63, FIN-00014 University of Finland, Finland (fax. +358 9191 25364, e-mail. esko.kankuri@ helsinki.fi)

$\mathrm{T}$ he colon mucosa in ulcerative colitis (UC) produces increased amounts of pro-inflammatory cytokines such as interleukin-1 beta (IL-1 $\beta)$, tumour necrosis factor-alpha (TNF- $\alpha$ ) and interleukin-6 (IL-6) (1-3). The main cellular sources of these cytokines are activated monocytes and macrophages (4-6). The increased production of these pro-inflammatory cytokines correlates with disease activity in inflammatory bowel diseases $(1,7)$ and their synthesis is implicated in the pathogenesis of the disease (6). In addition, inflamed tissue produces cytokine antagonists to endogenously control their actions and to limit inflammation (8). One of these cytokine antagonists is the IL-1 receptor antagonist (IL-1Ra), which binds to the IL-1 receptor and thereby suppresses IL-1 signalling (9).

Active inflammation in UC is also associated with increased expression of the inducible, calcium-independent nitric oxide (NO) synthase (iNOS, NOS-2) (10). iNOS is capable of producing high amounts of NO (11) and is 
regarded as the principal source of $\mathrm{NO}$ in gut inflammation $(12,13)$. The expression of iNOS is induced by certain proinflammatory stimuli such as IL- $1 \beta, \mathrm{TNF}-\alpha$ and bacterial products $(11,12)$. Increased iNOS activity and NO production contribute to inflammation and oxidative stress through the reaction of NO with superoxide leading to the formation of a highly cytotoxic oxidant, the peroxynitrite anion $(14,15)$. Small amounts of NO are produced for physiological purposes by the constitutively expressed, calcium-dependent, enzymes: endothelial (eNOS, NOS-3) and neuronal NOS (nNOS, NOS-1) (11). NO contributes to several central functions in immune regulation (16), and an NO-releasing aminosalicylate-derivative has been shown to exert beneficial effects on colon inflammation in experimental models $(17,18)$.

Recently, we showed that the inflammatory process associated with induction of iNOS in an acute model of rat colitis (19) was suppressed by a highly selective inhibitor of iNOS, $1400 \mathrm{~W}(20,21)$. Our finding agrees with other reports on the advantageous effects of NOS inhibitors in the treatment of experimentally induced colitis (22-27). In the present study we provide further insight into these mechanisms and investigate the effects of a selective iNOS inhibitor $1400 \mathrm{~W}$ on the release of pro-inflammatory cytokines from colon mucosa of patients with severe UC.

\section{Materials and Methods}

\section{Patients}

The patient characteristics are given in Table I. All patients were on oral steroids and 5-aminosalicylic acid (5-ASA). They underwent elective proctocolectomy because of severe disease, failure of conventional treatment, or because of adverse drug effects. As an indicator of the ongoing inflammation, the patients' mean blood leucocyte count at time of operation was $10.2 \pm 1.1 \times 10^{9} 1^{-1}$. Their disease was histopathologically verified as UC (Helsinki University Central Hospital Laboratory Diagnostics, Department of Pathology, Helsinki, Finland) from comparative samples as used in the present study. Two of seven patients had been diagnosed with pancolitis; the other patients had diagnosed inflammation of descending colon only. At time of collecting the mucosal samples, the descending colon was most inflamed by eye in all cases, whereas macroscopically uninflamed mucosa was present in the ascending and transverse colon.

\section{Incubation of colon mucosal samples}

Immediately after removal, the colon was longitudinally opened and $4 \mathrm{~cm}^{2}$ samples of mucosa were cut from inflamed and uninflamed regions. The samples were placed in separate containers containing $500 \mathrm{~mL}$ of ice-cold phosphate buffered saline (PBS) for transport. Thereafter (approximately after $15 \mathrm{~min})$ the tissues were washed in fresh ice-cold PBS. Mucosal samples were cut with a curette ( $4 \mathrm{~mL}$ in diameter). Each sample was placed in $800 \mu \mathrm{L}$ PBS in a cell culture plate. After $30 \mathrm{~min}$ pre-incubation, the PBS was replaced with $400 \mu \mathrm{L}$ of culture medium (RPMI 1640 containing antibiotics: penicillin $100 \mathrm{U} \mathrm{mL}^{-1}$, streptomycin $0.1 \mathrm{mg} \mathrm{mL}^{-1}$, and amphotericin B $250 \mathrm{ng} \mathrm{mL}^{-1}$ ) supplemented with the test compounds. Both uninflamed and inflamed mucosal samples were divided into four groups, one group with vehicle (culture medium only), one with L-NAME (1 mM), one with $1400 \mathrm{~W}$ $(1 \mathrm{mM})$, and one group with SNAP $(500 \mu \mathrm{M})$. The concentrations were chosen for sufficient mucosal tissue sample (50-60 mg) penetration by the drugs from the relatively small volume $(400 \mu \mathrm{L})$ of incubation medium. The culture plates were kept in a humidified atmosphere consisting of $95 \%$ air and $5 \% \mathrm{CO}_{2}$ at $37^{\circ} \mathrm{C}$ for $5 \mathrm{~h}$. After incubation, the medium and mucosal samples were collected and immediately frozen in liquid nitrogen and stored at $-70^{\circ} \mathrm{C}$ until analysed.

\section{Enzyme-linked immunosorbent assay (ELISA)}

Cytokines IL- $1 \beta$, IL- 6 and TNF- $\alpha$ were analysed by ELISA using reagents supplied by Central Laboratory of The Netherlands Red Cross (CLB), The Netherlands (PeliPair reagent sets). IL-1Ra was analysed by ELISA using reagents from R\&D Systems, USA (Quantikine ${ }^{\circledR}$ ).

\section{Immunohistochemistry}

Mucosal samples were embedded in Tissue Tek O. C. T. Compound (Sakura Finetek Inc., Zoeterwoude, The Netherlands). Cryostat sections were air dried and fixed in ice-cold methanol. Endogenous peroxidase activity was quenched with subsequent incubation in PBS containing $0.3 \%$ hydrogen

Table I. Patient characteristics

\begin{tabular}{|c|c|c|c|c|c|c|}
\hline \multirow[b]{2}{*}{$\#$} & \multirow[b]{2}{*}{ Male $(\mathrm{M}) /$ Female $(\mathrm{F})$} & \multirow[b]{2}{*}{ Age } & \multirow[b]{2}{*}{ Years from diagnosis } & \multicolumn{3}{|c|}{ Drug treatment at time of operation } \\
\hline & & & & Peroral steroid, mg/day & $5-\mathrm{ASA}^{*} \mathrm{mg} /$ day & Azathioprine mg/day \\
\hline 1 & M & 57 & 2 & Prednisone, $5+$ prednisolone, 25 rectally & 2400 & - \\
\hline 2 & $\mathrm{~F}$ & 31 & 8 & Prednisone, 10 & 3200 & - \\
\hline 3 & $\mathrm{~F}$ & 27 & 3.5 & Methylprednisolone, 40 & 3200 & - \\
\hline 4 & $\mathrm{~F}$ & 35 & 4 & Methylprednisolone, 24 & 2400 & - \\
\hline 5 & M & 32 & 1.5 & Prednisone, 20 & 3200 & - \\
\hline 6 & M & 44 & 5.5 & Prednisolone, 15 & 2400 & - \\
\hline 7 & $\mathrm{M}$ & 46 & 2.5 & Prednisone, 30 & 3200 & 75 \\
\hline
\end{tabular}

*5-ASA = 5-aminosalicylic acid. 
peroxide. The sections were then washed three times with icecold PBS, incubated in normal blocking serum, washed and incubated overnight with the primary antibody. Thereafter the sections were processed according to the avidin-biotinperoxidase procedure (Vectastain ABC Elite-kit, Vector Laboratories, Burlingame, Calif., USA). Monoclonal antiiNOS at a dilution of 1:2000 (Transduction Laboratories, Franklin Lakes, N.J., USA) and polyclonal anti-nitrotyrosine at a dilution of 1:500 (Upstate Biotechnology, Lake Placid, NY, USA) were used as primary antibodies. Respective nonimmune serum was used instead of primary or secondary antibody as negative controls. Rabbit/mouse IgG of the same sub-type as the primary antibody but with an irrelevant specificity was used as an additional negative control. The sections were counterstained with haematoxylin.

\section{Western blot}

Western blots for iNOS and nitrotyrosine were carried out using previously described protocols (21). The nitrotyrosine antibody was from Upstate Biotechnology, the monoclonal eNOS and nNOS antibodies were from Transduction Laboratories, and the monoclonal iNOS antibody was from Santa Cruz Biotechnology (Santa Cruz, Calif., USA). Densitometric analysis was carried out using specific computer programs GeneSnap Version 2.60.0.14 and GeneTools Version 2.10.03 (Synoptics, Cambridge, UK).

\section{Materials}

L-NAME and SNAP were purchased from Sigma Chemical Co. (St. Louis, Mo., USA). $1400 \mathrm{~W}$ was kindly provided by Dr. Richard G. Knowles, Glaxo SmithKline (Stevenage, UK). RPMI-1640 and the antibiotics were purchased from Gibco BRL (NY, USA). Culture plates were from Nunc (Copenhagen, Denmark) and curettes from Stiefel Laboratories Ltd. (Sligo, Ireland). a)



b)

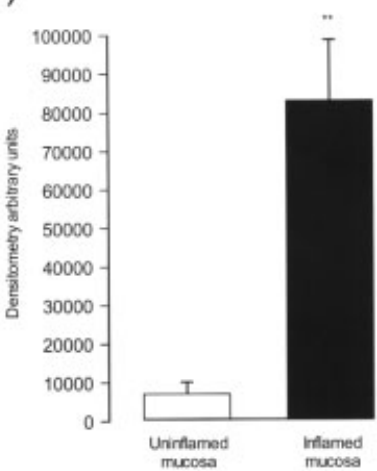

Fig. 1. (a) Expression of inducible nitric oxide synthase (iNOS) and (b) densitometry of iNOS expression in macroscopically inflamed and uninflamed, quiescent mucosal samples from the seven patients with ulcerative colitis. In (b), data are expressed as mean $\pm s_{\bar{x}}(\mathrm{SE})$ $* * P<0.01$ as compared to uninflamed mucosa.
Ethics

The study plan was approved by the Ethics Committee of Helsinki University Central Hospital, Dept. of Surgery, Helsinki, Finland.

\section{Statistics}

Statistical analyses for densitometric studies were carried out using two-tailed paired $t$ test, and for the drug treatment studies using the analysis of variance (ANOVA); intergroup comparisons were made using the Bonferroni's post-test, $P$ values $<0.05$ were considered significant. All data are expressed as mean $\pm s_{\bar{x}}$ (standard error of the mean).

\section{Results}

The expression of iNOS was about 10-fold higher in the inflamed samples of colon mucosa as compared to macroscopically healthy mucosa (Fig. 1). In contrast, no differences in the expressions of the constitutive NOS isoforms, eNOS and nNOS, were found between the inflamed and the quiescent mucosa (Figs. 2 and 3). Nitrotyrosine was measured as a marker of peroxynitrite production. Immunoblotting of nitrotyrosine expression in the inflamed mucosa revealed scantly, but non-significantly elevated levels of nitrotyrosine in inflamed mucosa as compared to the uninflamed samples (data not shown). Localization of iNOS and nitrotyrosine by immunohistochemistry showed their predominant expression in infiltrated inflammatory cells. iNOS was also localized to the apical epithelial brush border in some areas (Fig. 4).

All mucosal samples produced detectable amounts of IL-6, TNF- $\alpha$ and IL- $1 \beta$ into the culture medium. Incubation of the inflamed mucosa with the highly selective iNOS inhibitor $1400 \mathrm{~W}$ decreased the accumulation of IL- 6 by $27 \%$ and TNF- $\alpha$ by $66 \%$ (Fig. 5), but had no effect on IL-1 $\beta$ or IL-1Ra secretion as compared to untreated inflamed control samples a)



b)

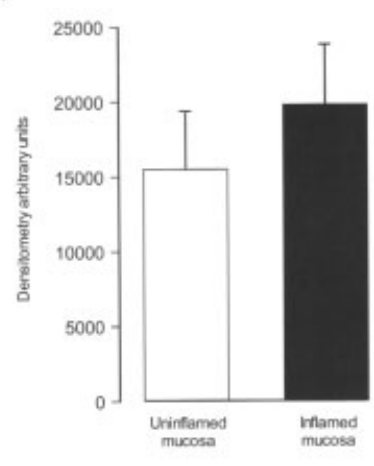

Fig. 2. (a) Expression of endothelial nitric oxide synthase (eNOS) and (b) densitometry of eNOS expression in macroscopically inflamed and uninflamed, quiescent mucosal samples from the seven patients with ulcerative colitis. In (b), data are expressed as mean $\pm s_{\bar{x}}(\mathrm{SE})$. 
a)

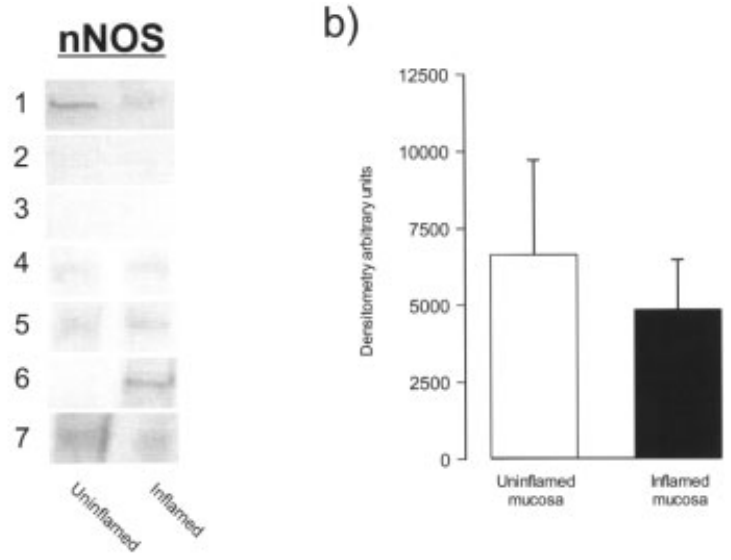

Fig. 3. (a) Expression of neuronal nitric oxide synthase (nNOS) and (b) densitometry of nNOS expression in macroscopically inflamed and uninflamed, quiescent mucosal samples from the seven patients with ulcerative colitis. In (b), data are expressed as mean $\pm s_{\bar{x}}$ (SE).

(Fig. 6). The relatively cNOS over iNOS selective inhibitor L-NAME had no significant effects on cytokine accumulation. In contrast, treatment with NO-donor SNAP increased the production TNF- $\alpha$ (by $62 \%$ ), IL-6 (by $52 \%$ ) and IL- $1 \beta$ (by $175 \%)$. SNAP also inhibited the production of IL-1Ra by $34 \%$ (Figs. 5 and 6) suggesting pro-inflammatory action of NOsupplementation in inflamed colitic mucosa.

Incubation of macroscopically uninflamed, quiescent mu-


Fig. 5. The effects of L-NAME, $1400 \mathrm{~W}$ and SNAP on concentrations of (a) tumour necrosis factor-alpha (TNF- $\alpha$ ), and (b) interleukin-6 (IL-6) in incubation medium of inflamed colon mucosa from the seven patients with UC. Data are expressed as mean $\pm s_{\bar{x}}$ (SE), $* P<0.05, * * * P<0.001$ as compared to untreated control. cosal samples with the selective iNOS inhibitor, $1400 \mathrm{~W}$, decreased TNF- $\alpha$ concentrations by $69 \%$ (Fig. 7), but had no effect on IL-6 (Fig. 7) or IL-1 $\beta$ (data not shown) concentrations. Interestingly, treatment of uninflamed mucosa with the NO-donor SNAP decreased IL- 6 accumulation by $48 \%$, but had no effect on TNF- $\alpha$ (Fig. 7) or IL-1 $\beta$ (data not shown). Treatment with L-NAME showed no significant effect on cytokine production by the uninflamed mucosa.

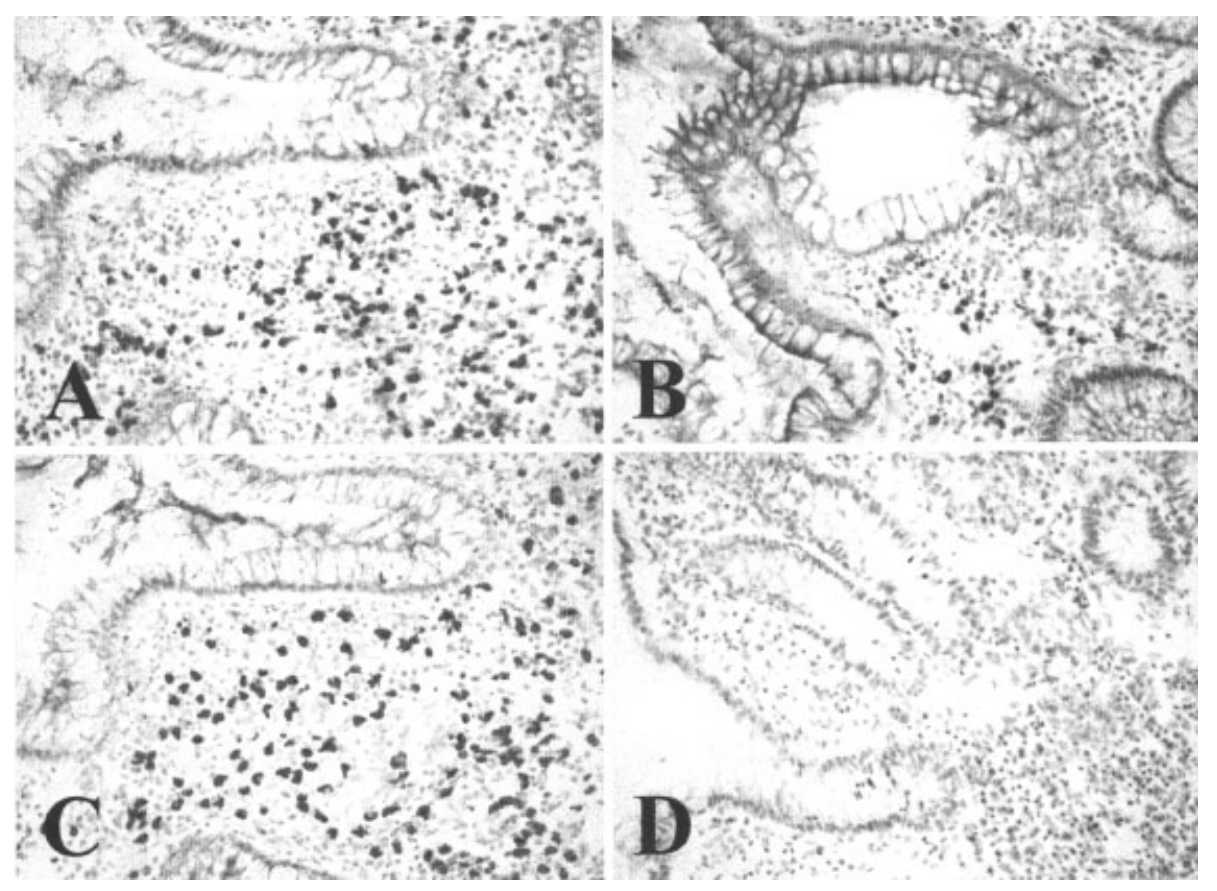

Fig. 4. Immunohistochemical localization of inducible nitric oxide synthase (iNOS) and nitrotyrosine in inflamed colon mucosa. (a) iNOS positive inflammatory cells in lamina propria, (b) iNOS positive staining in apical epithelial cell brush border, (c) nitrotyrosine positive staining in cells of lamina propria, and (d) negative control section incubated with non-immune serum instead of primary antibody. 
a)

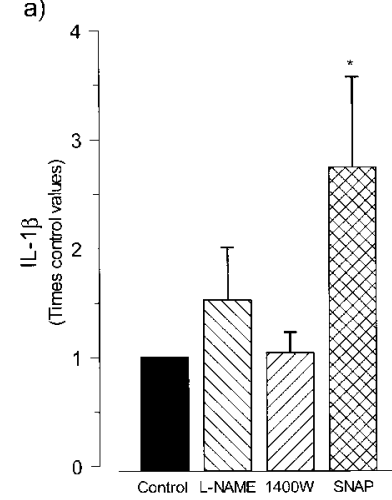

b)



Fig. 6. The effects of L-NAME, $1400 \mathrm{~W}$ and SNAP on concentrations of (a) interleukin-1 beta (IL-1 $\beta$ ) and (b) IL-1 receptor antagonist (IL-1Ra) in incubation medium of inflamed colon mucosa from the seven patients with UC. Data are expressed as mean $\pm s_{\bar{x}}$ (SE), $* P<0.05, * * P<0.01$ as compared to untreated control.

\section{Discussion}

Recently, we reported a beneficial effect of selective iNOS inhibition in a rat model of acute colitis (21). In the present study we investigated the effect of the highly selective iNOS inhibitor, $1400 \mathrm{~W}$, on the production of pro-inflammatory cytokines TNF- $\alpha$, IL- 6 and IL- $1 \beta$ in mucosal samples from patients with UC. In the inflamed colon mucosa, $1400 \mathrm{~W}$ suppressed the accumulation of TNF- $\alpha$ and IL- 6 in the incubation medium, while SNAP, and NO donor, increased their release. The iNOS selective inhibitor also decreased $\mathrm{TNF}-\alpha$ release from uninflamed mucosa. SNAP aggravated mucosal inflammation also by increasing IL- $1 \beta$ and suppressing IL-1Ra production thus causing a disruption of the IL-1 $\beta$ / IL-1Ra balance in active disease. These results suggest that selective iNOS inhibition may have anti-inflammatory effects in UC.



b)



Fig. 7. The effects of L-NAME, $1400 \mathrm{~W}$ and SNAP on concentrations of (a) tumour necrosis factor-alpha (TNF- $\alpha$ ) and (b) interleukin-6 (IL-6) in incubation medium of macroscopically uninflamed, quiescent colon mucosa from the seven patients with UC. Data are expressed as mean $\pm s_{\bar{x}}(\mathrm{SE}), * P<0.05, * * P<0.01$ as compared to untreated control.
Immunoblotting for iNOS, and marginally also for nitrotyrosine, showed their increase in the inflamed mucosa as compared with samples from uninflamed areas. The expression of iNOS and presence of nitrotyrosine were found predominantly in inflammatory cells of the lamina propria. iNOS was also found in the brush border of the epithelial cells. This pattern of iNOS and nitrotyrosine expression is supported by previous findings in inflammatory bowel disease $(28,29)$. Tyrosine nitration has been widely used as a marker of peroxynitrite formation. Despite the fact that peroxynitriteindependent mechanisms of tyrosine nitration exist (30), the formation of nitrotyrosine reflects the overall amount of local oxidative and nitrosative stress, and the production of different nitrating species (31). It is feasible to assume that an increased iNOS expression in the inflamed mucosa, as found in the present study, is capable of high-output generation of NO, which rapidly reacts with the superoxide anion produced by inflammatory cells leading to the formation of peroxynitrite and nitrotyrosine. In inflammatory conditions, iNOS may also produce superoxide and thus contribute directly to oxidative stress (32).

Incubation of inflamed mucosa with $1400 \mathrm{~W}$ reduced the release of IL- 6 and TNF- $\alpha$, suggesting that in the colitic mucosa of UC, iNOS activity stimulates and drives proinflammatory cytokine release. SNAP, on the other hand, increased the secretion of IL- $1 \beta$, IL- 6 , TNF- $\alpha$, whereas it decreased IL-1Ra release by the inflamed mucosa. These findings are in concert with the previously reported positive feedback mechanism of nitric oxide on cytokine release (33) and on TNF- $\alpha$ production in activated human neutrophils and mononuclear cells (34-36). In tissue devoid of macroscopic inflammation, treatment with the NO-donor SNAP significantly inhibited the accumulation of IL-6 showing the opposing anti-inflammatory potential of NO. Thus, the detrimental effects of $\mathrm{NO}$ can be enhanced in active disease, while in inactive disease NO may have anti-inflammatory activity.

Inflamed tissues produce IL-1Ra, a cytokine antagonist, which acts as an endogenous suppressor of the pro-inflammatory responses of IL-1 (37). Imbalanced production of IL-1 and IL-1Ra in UC aggravates the inflammatory reaction (38). In the inflamed colon mucosa, as seen in the present study, exogenous NO increased the production of IL- $1 \beta$ and decreased IL-1Ra. In light of these results, NO may exacerbate active mucosal inflammation by disrupting the IL1/IL1Ra balance even further.

The mechanisms through which the high-output NO generation by iNOS regulates cytokine release are not clear. The mitogen activated protein kinase (MAPK) cascade can be activated by peroxynitrite $(39)$ and NO $(40,41)$ resulting in enhanced activity of transcription factors such as NF- $\kappa \mathrm{B}$ and activating protein-1 (AP-1) $(42,43)$. The activation of NF- $\kappa \mathrm{B}$ is associated with increased production of IL- 6 and TNF- $\alpha$ (44-46), and the AP-1 family of transcriptional activators functions in cooperation with $\mathrm{NF}-\kappa \mathrm{B}$ contributing to for example increased transcription of TNF- $\alpha$ (42). It was 
recently reported that NO may augment cytokine-induced AP-1 activation also through cyclic-GMP-dependent protein kinase (47), suggesting that NO may have both direct and indirect actions on activation of pro-inflammatory cytokine genes (48). Also a more direct action of NO and oxidative stress has been reported on TNF- $\alpha$. They have been shown to activate the TNF- $\alpha$-converting enzyme, thus increasing TNF- $\alpha$ release $(49,50)$. These data are well in concert with the present results, since selective inhibition of iNOS, leading to decreased production of $\mathrm{NO}$ and peroxynitrite, inhibited TNF- $\alpha$ release from both inflamed and uninflamed samples.

We have previously shown that selective inhibition of iNOS with $1400 \mathrm{~W}$ decreases macroscopic mucosal lesions, inflammatory edema, and granulocyte infiltration in experimentally induced acute colitis in the rat (21). In that study, the NOS-inhibitor L-NAME, the selectivity of which favors cNOS over iNOS, produced no significant anti-inflammatory effects. The results of the present study further suggest that anti-inflammatory benefits are provided through selective inhibition of iNOS rather than inhibition of the constitutive NOS isoforms in colon inflammation. However, the detrimental role of iNOS in gut inflammation has been disputed $(51,52)$. Data from experimental models suggest that induction of iNOS may also contribute to resolution of inflammation (52), and that a basal, physiological induction of iNOS in the gut is required for prevention of bacterial overgrowth (53). Even though iNOS seems to have protective effects in gut mucosa (54), the pathological actions, e.g. oxidative and nitrosative stress related NO-metabolism and persistent T-cell activation in chronic inflammatory disease may overcome or prevent these beneficial actions.

In conclusion, our results support the hypothesis that selective inhibition of iNOS down-regulates mucosal inflammation by suppressing TNF- $\alpha$ and IL- 6 production in UC-mucosa. These results warrant further investigation of NO-related therapies, and suggest that selective inhibitors of iNOS have therapeutic potential in the treatment of UC.

\section{Acknowledgements}

We thank Dr. Richard G. Knowles (GlaxoSmithKline Research, UK) for providing $1400 \mathrm{~W}$, and Professor Heikki J. Järvinen for his help and expertise. We are grateful to Ms Lahja Eurajoki, Ms Nina Ikonen, Ms Marja-Leena Lampen, and Ms Pirkko Möller for their diligent and skillful technical assistance, and to Ms Eeva Harju and Ms Heli Määttä for their expert secretarial help.

\section{References}

1. Reimund JM, Wittersheim C, Dumont S, Muller CD, Baumann $\mathrm{R}$, Poindron $\mathrm{P}$, et al. Mucosal inflammatory cytokine production by intestinal biopsies in patients with ulcerative colitis and Crohn's disease. J Clin Immunol 1996;16:144-50.
2. Rogler G, Andus T. Cytokines in inflammatory bowel disease. World J Surg 1998;22:382-9.

3. Stevens C, Walz G, Singaram C, Lipman ML, Zanker B, Muggia A, et al. Tumor necrosis factor-alpha, interleukin-1 beta, and interleukin-6 expression in inflammatory bowel disease. Dig Dis Sci 1992;37:818-26.

4. Dinarello CA. The interleukin-1 family: 10 years of discovery. FASEB J 1994;8:1314-25.

5. Hosokawa T, Kusugami K, Ina K, Ando T, Shinoda M, Imada $A$, et al. Interleukin- 6 and soluble interleukin- 6 receptor in the colonic mucosa of inflammatory bowel disease. J Gastroenterol Hepatol 1999;14:987-96.

6. Papadakis KA, Targan SR. Tumor necrosis factor: biology and therapeutic inhibitors. Gastroenterology 2000;119:1148-57.

7. Ishiguro $Y$. Mucosal proinflammatory cytokine production correlates with endoscopic activity of ulcerative colitis. J Gastroenterol 1999;34:66-74.

8. Daig R, Rogler G, Aschenbrenner E, Vogl D, Falk W, Gross V, et al. Human intestinal epithelial cells secrete interleukin-1 receptor antagonist and interleukin- 8 but not interleukin-1 or interleukin-6. Gut 2000;46:350-8.

9. Noguchi M, Hiwatashi N, Liu Z, Toyota T. Secretion imbalance between tumour necrosis factor and its inhibitor in inflammatory bowel disease. Gut 1998;43:203-9.

10. Godkin AJ, De Belder AJ, Villa L, Wong A, Beesley JE, Kane $\mathrm{SP}$, et al. Expression of nitric oxide synthase in ulcerative colitis. Eur J Clin Invest 1996;26:867-72.

11. Alderton WK, Cooper CE, Knowles RG. Nitric oxide synthases: structure, function and inhibition. Biochem J 2001;357:593-615.

12. Kolios G, Rooney N, Murphy CT, Robertson DA, Westwick J. Expression of inducible nitric oxide synthase activity in human colon epithelial cells: modulation by $\mathrm{T}$ lymphocyte derived cytokines. Gut 1998;43:56-63.

13. Salzman AL, Eaves-Pyles T, Linn SC, Denenberg AG, Szabo C. Bacterial induction of inducible nitric oxide synthase in cultured human intestinal epithelial cells. Gastroenterology 1998;114:93102 .

14. Beckman JS, Koppenol WH. Nitric oxide, superoxide, and peroxynitrite: the good, the bad, and ugly. Am J Physiol 1996;271: C1424-37.

15. Schmidt HHHW, Walter U. NO at work. Cell 1994;78:919-25.

16. Bogdan C. Nitric oxide and the immune response. Nat Immunol 2001;2:907-16.

17. Fiorucci S, Distrutti E, Ajuebor MN, Mencarelli A, Mannucci R, Palazzetti B, et al. NO-mesalamine protects colonic epithelial cells against apoptotic damage induced by proinflammatory cytokines. Am J Physiol Gastrointest Liver Physiol 2001;281: G654-65.

18. Wallace JL, Vergnolle N, Muscara MN, Asfaha S, Chapman K, McKnight W, et al. Enhanced anti-inflammatory effects of a nitric oxide-releasing derivative of mesalamine in rats. Gastroenterology 1999; 117:557-66.

19. Kankuri E, Asmawi MZ, Korpela R, Vapaatalo H, Moilanen E. Induction of iNOS in a rat model of acute colitis. Inflammation 1999;23:141-52.

20. Garvey EP, Oplinger JA, Furfine ES, Kiff RJ, Laszlo F, Whittle $\mathrm{BJ}$, et al. $1400 \mathrm{~W}$ is a slow, tight binding, and highly selective inhibitor of inducible nitric-oxide synthase in vitro and in vivo. J Biol Chem 1997;272:4959-63.

21. Kankuri E, Vaali K, Knowles RG, Lähde M, Korpela R, Vapaatalo H, et al. Suppression of acute experimental colitis by a highly selective inducible nitric-oxide synthase inhibitor, N[3-(aminomethyl)benzyl]acetamidine. J Pharmacol Exp Ther 2001;298:1128-32.

22. Kiss J, Lamarque D, Delchier JC, Whittle BJ. Time-dependent actions of nitric oxide synthase inhibition on colonic inflammation induced by trinitrobenzene sulphonic acid in rats. Eur $\mathbf{J}$ Pharmacol 1997;336:219-24.

23. Menchen LA, Colon AL, Moro MA, Leza JC, Lizasoain I, Menchen $\mathrm{P}$, et al. N-(3-(aminomethyl)benzyl)acetamidine, an inducible nitric oxide synthase inhibitor, decreases colonic inflammation induced by trinitrobenzene sulphonic acid in rats. Life Sci 2001;69:479-91. 
24. Nakamura H, Tsukada H, Oya M, Onomura M, Saito T, Fukuda $\mathrm{K}$, et al. Aminoguanidine has both an anti-inflammatory effect on experimental colitis and a proliferative effect on colonic mucosal cells. Scand J Gastroenterol 1999;34:1117-22.

25. Neilly PJ, Kirk SJ, Gardiner KR, Anderson NH, Rowlands BJ. Manipulation of the L-arginine-nitric oxide pathway in experimental colitis. Br J Surg 1995;82:1188-91.

26. Pfeiffer CJ, Qiu BS. Effects of chronic nitric oxide synthase inhibition on TNB-induced colitis in rats. J Pharm Pharmacol 1995;47:827-32.

27. Rachmilewitz D, Karmeli F, Okon E, Bursztyn M. Experimental colitis is ameliorated by inhibition of nitric oxide synthase activity. Gut 1995;37:247-55.

28. Kimura H, Hokari R, Miura S, Shigematsu T, Hirokawa M, Akiba Y, et al. Increased expression of an inducible isoform of nitric oxide synthase and the formation of peroxynitrite in colonic mucosa of patients with active ulcerative colitis. Gut 1998;42:180-7.

29. Singer II, Kawka DW, Scott S, Weidner JR, Mumford RA, Rieh TE, et al. Expression of inducible nitric oxide synthase and nitrotyrosine in colonic epithelium in inflammatory bowel disease. Gastroenterology 1996;111:871-85.

30. Davis KL, Martin E, Turko IV, Murad F. Novel effects of nitric oxide. Annu Rev Pharmacol Toxicol 2001;41:203-36.

31. Broillet MC. S-nitrosylation of proteins. Cell Mol Life Sci 1999; 55:1036-42

32. Xia Y, Zweier JL. Superoxide and peroxynitrite generation from inducible nitric oxide synthase in macrophages. Proc Natl Acad Sci USA 1997;94:6954-8.

33. Marcinkiewicz J, Grabowska A, Chain B. Nitric oxide upregulates the release of inflammatory mediators by mouse macrophages. Eur J Immunol 1995;25:947-51.

34. Eigler A, Sinha B, Endres S. Nitric oxide-releasing agents enhance cytokine-induced tumor necrosis factor synthesis in human mononuclear cells. Biochem Biophys Res Commun 1993;196:494-501.

35. Lander HM, Sehajpal P, Levine DM, Novogrodsky A. Activation of human peripheral blood mononuclear cells by nitric oxide-generating compounds. J Immunol 1993;150:1509-16.

36. Van Dervort AL, Yan L, Madara PJ, Cobb JP, Wesley RA, Corriveau CC, et al. Nitric oxide regulates endotoxin-induced TNF-alpha production by human neutrophils. J Immunol 1994; 152:4102-9.

37. Arend WP, Malyak M, Guthridge CJ, Gabay C. Interleukin-1 receptor antagonist: role in biology. Annu Rev Immunol 1998; 16:27-55.

38. Casini-Raggi V, Kam L, Chong YJ, Fiocchi C, Pizarro TT, Cominelli F. Mucosal imbalance of IL-1 and IL-1 receptor antagonist in inflammatory bowel disease. A novel mechanism of chronic intestinal inflammation. J Immunol 1995;154:2434 440.

39. Bapat S, Verkleij A, Post JA. Peroxynitrite activates mitogenactivated protein kinase (MAPK) via a MEK-independent pathway: a role for protein kinase C. FEBS Lett 2001;499:21-6.
40. Karin M. The regulation of AP-1 activity by mitogen-activated protein kinases. J Biol Chem 1995;270:16483-6.

41. Lander HM, Jacovina AT, Davis RJ, Tauras JM. Differential activation of mitogen-activated protein kinases by nitric oxiderelated species. J Biol Chem 1996;271:19705-9.

42. Foletta VC, Segal DH, Cohen DR. Transcriptional regulation in the immune system: all roads lead to AP-1. J Leukoc Biol 1998; 63:139-52.

43. Ghosh S, May MJ, Kopp EB. NF-kappa B and Rel proteins: evolutionarily conserved mediators of immune responses. Annu Rev Immunol 1998;16:225-60.

44. Baeuerle PA, Henkel T. Function and activation of NF-kappa B in the immune system. Annu Rev Immunol 1994;12:141-79.

45. Neurath MF, Fuss I, Schurmann G, Pettersson S, Arnold K, Muller-Lobeck $\mathrm{H}$, et al. Cytokine gene transcription by NFkappa B family members in patients with inflammatory bowel disease. Ann NY Acad Sci 1998;859:149-59.

46. Rogler G, Brand K, Vogl D, Page S, Hofmeister R, Andus T, et al. Nuclear factor kappa B is activated in macrophages and epithelial cells of inflamed intestinal mucosa. Gastroenterology 1998;115:357-69.

47. Felley-Bosco E, Ambs S, Lowenstein CJ, Keefer LK, Harris CC. Constitutive expression of inducible nitric oxide synthase in human bronchial epithelial cells induces c-fos and stimulates the cGMP pathway. Am J Respir Cell Mol Biol 1994; 11: 15964.

48. Gertzberg N, Clements R, Jaspers I, Ferro TJ, Neumann P, Flescher E, et al. Tumor necrosis factor-alpha-induced activating protein-1 activity is modulated by nitric oxide-mediated protein kinase G activation. Am J Respir Cell Mol Biol 2000;22: $105-15$.

49. Zhang Z, Kolls JK, Oliver P, Good D, Schwarzenberger PO, Joshi MS, et al. Activation of tumor necrosis factor-alphaconverting enzyme-mediated ectodomain shedding by nitric oxide. J Biol Chem 2000;275:15839-44.

50. Zhang Z, Oliver P, Lancaster JR, Jr, Schwarzenberger PO, Joshi MS, Cork J, et al. Reactive oxygen species mediate tumor necrosis factor alpha-converting enzyme-dependent ectodomain shedding induced by phorbol myristate acetate. FASEB J 2001; $15: 303-5$.

51. Kubes P. Inducible nitric oxide synthase: a little bit of good in all of us. Gut 2000;47:6-9.

52. McCafferty DM, Mudgett JS, Swain MG, Kubes P. Inducible nitric oxide synthase plays a critical role in resolving intestinal inflammation. Gastroenterology 1997;112:1022-7.

53. Roberts PJ, Riley GP, Morgan K, Miller R, Hunter JO, Middleton SJ. The physiological expression of inducible nitric oxide synthase (iNOS) in the human colon. J Clin Pathol 2001; 54:293-7.

54. Wallace JL, Miller MJ. Nitric oxide in mucosal defense: a little goes a long way. Gastroenterology 2000;119:512-20. 